Article

\title{
Seismic Vulnerability Assessment of Existing Reinforced Concrete Buildings in Urban Centers
}

\author{
Tiago Miguel Ferreira ${ }^{1, *(\mathbb{D}}$, Hugo Rodrigues ${ }^{2} \mathbb{D}$ and Romeu Vicente ${ }^{3}$ \\ 1 ISISE-Institute of Science and Innovation for Bio-Sustainability (IB-S), Department of Civil Engineering, \\ University of Minho, 4400-058 Guimarães, Portugal \\ 2 RISCO, Department of Civil Engineering, Polytechnic Institute of Leiria, 2411-901 Leiria, Portugal; \\ hugo.f.rodrigues@ipleiria.pt \\ 3 RISCO, Department of Civil Engineering, University of Aveiro, 3810-193 Aveiro, Portugal; romvic@ua.pt \\ * Correspondence: tmferreira@civil.uminho.pt
}

Received: 17 January 2020; Accepted: 4 March 2020; Published: 5 March 2020

check for updates

\begin{abstract}
Despite the recent advances in the analysis of the seismic performance of reinforced concrete structures, the assessment of large building inventories aimed at defining and prioritizing structural retrofitting strategies is still a technically challenging task. This paper aims to contribute to bridging this gap by presenting a simplified methodology for assessing the seismic vulnerability of reinforced concrete buildings, which is then applied to a group of 91 buildings affected by recent earthquakes with different macroseismic intensities. The presented methodology is based on the evaluation of eight parameters associated with different factors that affect the seismic response of the building, namely its structural features, foundation conditions, and position within the urban mesh. The formulation of each parameter and the relative weight attributed to each one of them were defined on the basis of post-earthquake damage observation and expert opinion. After defined, the proposed methodology is applied to Faro city center. Based on the results obtained, a cost benefit analysis is made considering a strengthening solution to the buildings with soft-story irregularity.
\end{abstract}

Keywords: seismic vulnerability index; RC buildings; damage mechanisms; damage scenarios

\section{Introduction}

It is undeniable that in medium/high seismic prone areas, human and economic loss is due to severe physical damage levels of construction and partial or total collapse of non-seismically designed or strengthened buildings. The lack of specific guidelines, in the form of provision codes, is not the only reason for such a context, but also the unprepared technical and professional community to carry out strengthening measures with quality control and specialized craft. In conceptual terms, the seismic risk is a function of three probabilistic components: hazard, exposure, and vulnerability. In the case of civil engineering structures, the last component assumes particular importance, since strengthening measures help the reduction of the intrinsic vulnerability of buildings, consequently reducing the seismic risk. Therefore, there is a need to develop simplified procedures, to mitigate the effects of such extreme events, which are scientifically supported and, at the same time, are intelligible to the non-technical community, owners, and decision-makers. In order to assess the structural vulnerability, it is fundamental to use approaches suitable for the assessment scale pursued (regional district, urban area, aggregate, singular building). Therefore, the qualitative or quantitative nature of the approach to adopt must be limited by the level of detail and building information available.

Empirical approaches are based on the analysis of the distribution of post-earthquake damage among categorical states associated with different building typologies and macroseismic intensities. Analytical approaches imply computational effort and the detailed modeling of the structure that in 
many cases, should be the representative of a specific building typology using mean values for the mechanical properties and geometrical layout. Moreover, there are different approaches, heuristically based, in which seismic vulnerability of buildings is attributed based on expert opinion [1,2]. Among the several simplified seismic vulnerability assessment approaches that could be cited here, the P25 scoring method, proposed by [3], the "Rapid Visual Screening of Buildings for Potential Seismic Hazards" presented by ATC-21 [4], and the methodologies proposed by GNDT II [5] and by [6-8] are worthy of note.

Based on the exposed, this work is presented and discussed in three parts. In the first part, the proposed methodology for evaluating the seismic vulnerability of the existing Reinforced Concrete (RC) building is described, along with the discussion of the parameters considered for the definition of vulnerability classes and the attribution of the individual weights. The second part consists of the attribution of a mean damage grade to a group of 91 buildings, evaluated and classified in accordance to the European Macroseismic Scale (EMS-98) [9], from which a vulnerability function was derived for this specifically for RC buildings. The backbone of the assessment procedure presented in the following sections is based on a similar approach developed for masonry building typology and successfully applied and improved in the scope of many past research projects [10-12]. Finally, the third part reflects the application of the calibrated methodology to Faro city center, in Portugal, considering the original buildings and evaluating the effect of the implementation of the strengthening measures.

\section{Seismic Vulnerability Assessment of Reinforced Concrete Frame Buildings}

As thoroughly discussed in [2], a methodology to assess the seismic vulnerability of a building should consider its typology, the scale of the assessment, and resources available (economic and human). The methodology presented herein, based on post-earthquake damage observation and expert opinion, is thought to be a rapid screening approach to aid identifying more fragile and damage-prone buildings in the case of a strong earthquake.

As already referred, the method was inspired in similar approaches for traditional masonry buildings [13]. Conceptually, it is composed of 8 evaluation parameters, divided into three groups associated with factors related to foundation conditions, building position within the urban mesh, structural features. The first group includes parameter P1, which assesses the soil and foundation conditions and typology. Group 2 includes parameter P2, which assesses the interaction with neighboring buildings. The third group includes parameters $\mathrm{P} 3$ to $\mathrm{P} 8$, which respectively assesses the building age, eventual irregularity in plan and height, the existence of potential conditions for short-column, and soft-story mechanisms and the presence of other vulnerable elements that influence the seismic vulnerability. Since one of the main objectives of the approach is to be simplified and based on visual observation, seismic detailing is implicitly assessed by the parameters in group 3, namely by parameter P3 ("Building Age"), which evaluates the compliance of the building to the seismic and structural requirements of the code in force when the building was built in respect to current seismic capacity design criteria and ductility rules. Hence, in particular, this parameter is to be defined regionally, redefining its vulnerability classes and criteria, due to differences from low to high seismically prone areas and countries [14].

\subsection{A Seismic Vulnerability Index for RC Buildings}

The proposed methodology evaluates the vulnerability index for each RC building based on eight parameters, as stated before. These parameters are classified in accordance to four vulnerability classes $\left(C_{\mathrm{vi}}\right): A, B, C$, and $D$. As referred before, each parameter evaluates a specific feature that influences the seismic response of each building, by choosing the vulnerability class that best applies to the building under analysis. To each parameter is associated a weight, $\mathrm{p}_{\mathrm{i}}$, ranging from 0.5 for the less important parameters to 2 for the parameters with most impact over the seismic vulnerability of the building (see Table 1). 
Table 1. Parameters of the vulnerability index, $I_{V}$, with respective vulnerability classes and weights.

\begin{tabular}{|c|c|c|c|c|c|c|}
\hline \multirow{2}{*}{\multicolumn{2}{|c|}{ Parameter }} & \multicolumn{4}{|c|}{ Class $C_{v i}$} & \multirow{2}{*}{$\begin{array}{c}\text { Weight } \\
p_{i}\end{array}$} \\
\hline & & $\mathbf{A}$ & B & $\mathrm{C}$ & $\mathbf{D}$ & \\
\hline \multicolumn{7}{|c|}{ Group 1. Foundations } \\
\hline P1 & Building implantation & 0 & 5 & 20 & 50 & 1.5 \\
\hline \multicolumn{7}{|c|}{ Group 2. Relative position } \\
\hline $\mathrm{P} 2$ & Building position & 0 & 5 & 20 & 50 & 0.5 \\
\hline \multicolumn{7}{|c|}{ Group 3. Structural features } \\
\hline P3 & Building age & 0 & 5 & 20 & 50 & 1.5 \\
\hline $\mathrm{P} 4$ & Irregularity in plan & 0 & 5 & 20 & 50 & 2.0 \\
\hline P5 & Irregularity in height & 0 & 5 & 20 & 50 & 2.0 \\
\hline P6 & Soft-story mechanism & 0 & - & - & 50 & 2.0 \\
\hline P7 & Presence of short columns & 0 & 5 & 20 & 50 & 2.0 \\
\hline P8 & Presence of other vulnerable elements & 0 & 5 & 20 & 50 & 0.5 \\
\hline
\end{tabular}

The parameters included in Group 1 and Group 2 are related to the building position. The parameter P1 combines the evaluation of the type of soil and the foundations' conditions of the buildings. The soils types considered are related to the ones prescribed in the Eurocode 8 and should be defined based on information available about the soil, in the case of no available information, it should be considered a soil type B. The vulnerability classes are presented in Table 2.

Table 2. Vulnerability classes of P1.

\begin{tabular}{cccc}
\hline \multirow{2}{*}{ Type of Soil } & \multicolumn{4}{c}{ Building Location } \\
\cline { 2 - 4 } & Plain Field & Landfills & Pronounced Slope \\
\hline Soil type A & A & B & C \\
\hline Soil type B and C & B & C & D \\
\hline Soil type D and E & C & D & D \\
\hline
\end{tabular}

Parameter P2 is related to the building relative position with the adjacent buildings. To characterize the building vulnerability class, it is necessary, in a first step, to define the building relative position to the neighbor buildings (see Figure 1).

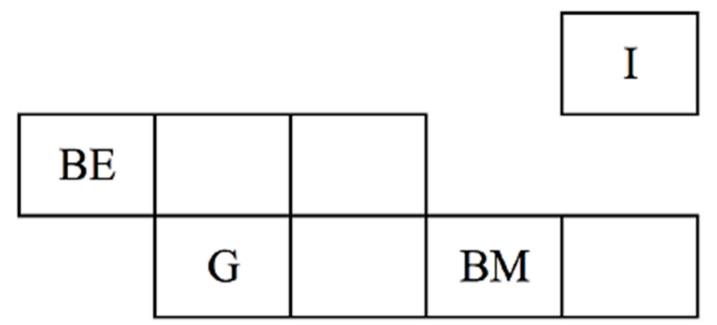

Figure 1. The criterion to assess parameter P2, where BM stands for in row building, I for isolated building, G for corner building, and BE for edge building.

Four different positions were considered, corresponding to different vulnerability classes: in row buildings (BM) are classified with vulnerability class $\mathrm{A}$, isolated buildings (I) are classified with vulnerability class $B$, corner buildings $(G)$ are classified with vulnerability class $C$, and edge buildings (BE) are classified with vulnerability class D. The classes are aggravated, to account for the interactions, 
namely due to the pounding with neighbor buildings. It should be considered the total height of the buildings under analysis and the adjacent buildings, if there is a presence of a significant difference in the total high of the building (more than one story), the vulnerability class should increase in one grade. Another essential aspect, to consider, is related to buildings with similar heights, but with misalignment between floors, which can introduce severe damages in the columns due to the interaction between buildings. In order to include this effect, the vulnerability class should be increased in one class in buildings with similar heights and with floor misalignment higher than $0.5 \mathrm{~m}$.

Group 3 is related to the structural characteristics of the building. Parameter P3 addresses the period of design and construction of the building (see Table 3). This parameter should be related to the year of the building design and the seismic provisions codes considered. For example, for the Portuguese context, it was considered class $D$ for buildings without seismic design, class $C$ for buildings designed/built between 1961 and 1983, for the class B the building built between 1983 and 2018, and for the class A the building built after 2018, considering the Eurocode 8 provisions. Besides the design philosophy and codes evolutions, the quality of design details and the quality of construction can play a significant role, as in the cases $\mathrm{A}$ to $\mathrm{C}$, a poor design/construction process is detected, the vulnerability class should be increased in one grade.

Table 3. The class definition for parameter P3.

\begin{tabular}{cc}
\hline Class & Design Type \\
\hline A & With modern seismic design codes \\
\hline B & With current seismic provisions \\
\hline C & With minor seismic provision \\
\hline D & Without seismic design \\
\hline
\end{tabular}

Parameters P4 and P5 are related to the structural regularity of the buildings. The plan regularity, assessed by parameter $\mathrm{P} 4$, is evaluated considering the number of sources of plan irregularities (see Table 4) and is related to the basic concepts included in the Eurocode 8. The parameter should evaluate: (i) the position of the elevator shaft in the building; (ii) the building plan slenderness (the largest side of the building plan should not be four times higher than the smaller side); (iii) check the compact plan configuration.

Table 4. Class definition for parameter P4.

\begin{tabular}{cc}
\hline Class & Plan Irregularity \\
\hline A & Building regular in plan \\
\hline B & Building with one source of plan irregularity \\
\hline C & Building with two sources of plan irregularity \\
\hline D & Building with more than two sources of plan irregularity \\
\hline
\end{tabular}

Regarding the parameter P5, related to the vertical regularity, it is important to evaluate the possible setbacks, the vertical loads' path discontinuities, and the difference in height between floors.

The parameter P6 evaluates the eventual presence of a possible soft-story mechanism. The soft-story mechanism is also related to an irregularity in height. Usually, this mechanism can occur on the ground floor due to architectural reasons or for spaces used for commercial uses. The difference in the strength or stiffness between the ground and upper floors leads to a concentration of deformation demand on the ground floor. When this occurs, the ground floor columns are subject to large deformation demand and may lead to an unexpected collapse mechanism. Even considering the vertical irregularities in parameter P5, the methodology gives an additional importance to this parameter, as is considered 
with class A for a building without a possible soft-story mechanism and class $\mathrm{D}$ for a building with a potential soft-story mechanism.

Parameter P7 is devoted to the evaluation of the presence of short columns. In many cases, due to the presence of openings (windows and doors), the masonry infill walls do not fulfill the height of the frame entirely, leaving a part of the columns unrestricted. These cases may lead to unexpected higher shear loads leading to the shear failure of the column. The definition of the vulnerability classes for P7 is presented in Table 5 .

Table 5. Class definition for parameter P7.

\begin{tabular}{cc}
\hline Class & Short Columns \\
\hline A & Building without short columns \\
\hline B & Building with possible short columns in one of the upper floors \\
\hline C & Building with possible short columns on the ground floor or in several stories of the upper floors. \\
\hline D & Building with possible short columns on the ground floor that may lead to a stories mechanism \\
\hline
\end{tabular}

Finally, parameter P8 is related to the presence of secondary elements, namely balconies, parapets, cornices, and appendages, which may lead to an increase in the risk to persons or aggravate the level of damage in the structural elements. The definition of the vulnerability classes for parameter P8 is given in Table 6.

Table 6. Class definition for parameter P8.

\begin{tabular}{cc}
\hline Class & Identification of Non-Structural Components \\
\hline A & Building without vulnerable non-structural components \\
\hline B & Building with parapets and/or cornices and/or appendages \\
\hline C & Building with balconies \\
\hline D & Building with balconies and parapets or cornices or appendages \\
\hline
\end{tabular}

The vulnerability index, $I_{v}{ }^{*}$, calculated using Equation (1), ranges from 0 to 600 . However, for more straightforward interpretation and use, this index is normalized to the range between 0 and 100, assuming then the format $I_{v}$ :

$$
I_{v}^{*}=\sum_{i=1}^{8} C_{v i} \times p_{i}
$$

As observed in Table 1, parameters P4 and P5, related to building irregularity in height and plan, and parameters P6 and P7, related to the presence of short column and soft-story mechanisms, are the most influent over the vulnerability index calculation, with a weight of 2.0.

\subsection{Calibration of the Methodology}

Since the present proposal aims to be suitable for assessing the seismic vulnerability of RC structures not designed for a specific country or location, it was calibrated with the data from $91 \mathrm{RC}$ buildings spread throughout the world that were affected by earthquakes with different intensities. As depicted in Figure 2, data were used from Japan, China, Italy, Peru, Spain, Turkey, United States, Haiti, New Zealand, Indonesia, and Mexico. To perform the assessment and evaluation of these buildings, photographic and technical reports gathered and developed by academic and research institutions in the scope of reconnaissance and post-earthquake missions were used. In some of the cases, the information was complemented with other sources of information, such as plans, elevations and structural design drawings, material testing, as well as geotechnical information. As will be discussed further, in those cases, the confidence factor associated with the evaluation is naturally higher than in the remaining. 


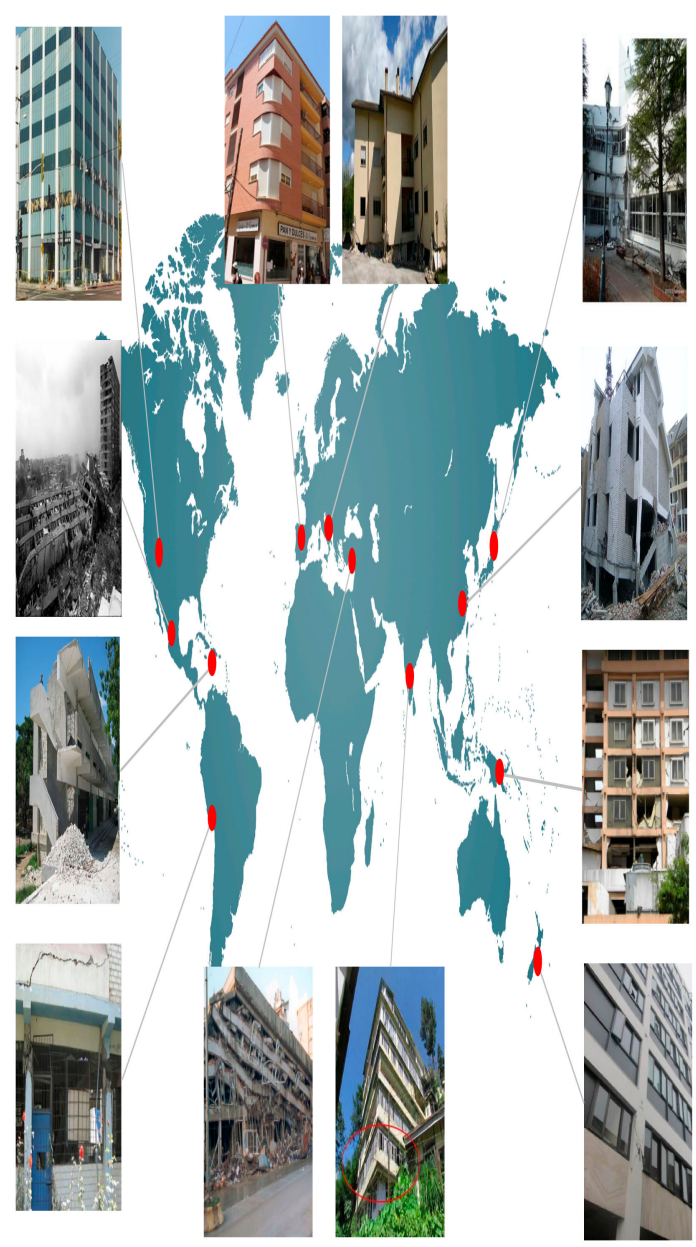

Figure 2. Geographical distribution of groups of buildings assessed.

The method was applied to the selected buildings and the overall results are presented and discussed next, in terms of vulnerability index and confidence factor. The results show a mean vulnerability index, $I_{v}$, of 38.73, with the standard deviation, $\sigma_{I v}$, of 12.30. Figure 3 presents the histogram of the vulnerability index values obtained. The range between 30 and 40 presents the highest fraction of vulnerability index values, containing $30 \%$ of the buildings. Forty-five percent of the building stock has an $I_{v}$ over 40 , and about $18 \%$ has a value over 50 . The maximum and minimum values calculated were 75 and 7.5 , respectively.

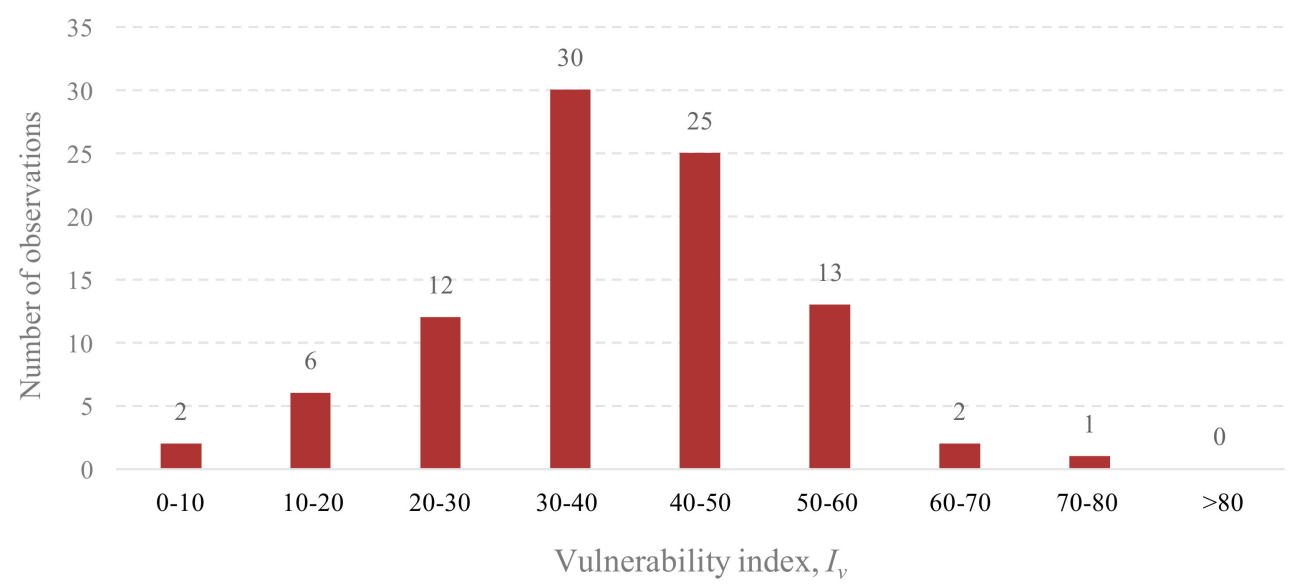

Figure 3. Distribution of the analyzed buildings over ranges of vulnerability index values. 
Figure 4 presents the vulnerability classes distribution of the evaluation parameters over the percentage of buildings assessed. From the analysis of Figure 4, it is possible to observe that parameter P6, which assesses the soft-story mechanism, is the one that presents the higher number of buildings belonging to vulnerability class $\mathrm{D}$ (about $70 \%$ of the buildings assessed), followed by parameter P3, which accounts for the age of the building, with about $28 \%$. Parameter P7, dedicated to the short columns, and parameter P8, which assesses the presence of non-structural elements, are the third and the fourth parameter with a higher percentage of buildings evaluated with vulnerability class $\mathrm{A}$, with about $69 \%$ and $43 \%$, respectively.

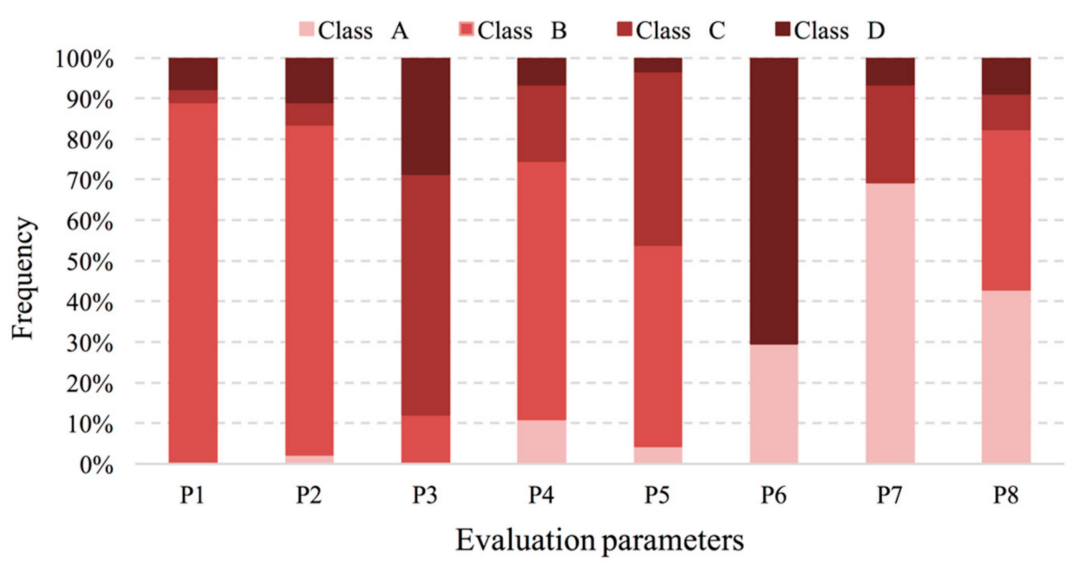

Figure 4. Influence of each one of the evaluation parameters on the final value of $I_{v}$.

The evaluation of each parameter has further involved the consideration of a confidence factor $(\mathrm{CF})$, which reflects the confidence in the evaluation of each one of the parameters, taking into account the detail and the trustworthiness of the information used. The uncertainty in the attribution of the parameter's class can have different origins, such as the impossibility of observing a specific structural or constructive element directly, or the total lack of information. The confidence factors attributed were: E (Elevated); M (Medium); B (Low); and A (Absent), according to Table 7. In order to treat and express these results numerically, there was a need to divide the confidence factors in 3 intermediate degrees between the main confidence factors (for example, $\mathrm{A}+\mathrm{A} / \mathrm{B}$, and $\mathrm{B}$ - between degrees $\mathrm{A}$ and $\mathrm{B}$ ).

Table 7. General definition of the four levels of confidence factor, adapted from [13].

\begin{tabular}{|c|c|}
\hline Class & Description \\
\hline $\mathrm{E}$ & $\begin{array}{l}\text { Information obtained from a direct source, that is, through visual in situ observation, } \\
\text { through local surveys that allow to assess the real building conditions or even by } \\
\text { consulting the project (information with a degree of confidence close to accurate). }\end{array}$ \\
\hline $\mathrm{M}$ & $\begin{array}{l}\text { Information predominantly deduced, through indirect sources, i.e., through consultation of } \\
\text { photographs, non-destructive tests, observation of direct information from similar } \\
\text { neighbouring buildings, collection of technical opinions, and credible oral information. }\end{array}$ \\
\hline B & $\begin{array}{l}\text { Information presumed in reasonable hypotheses of usual and common procedures of } \\
\text { execution at the time, tradition of construction in the region, and variable oral information. }\end{array}$ \\
\hline $\mathrm{A}$ & $\begin{array}{l}\text { Information adopted with a low confidence. In this case, the assignment of the } \\
\text { parameter class is purely indicative. }\end{array}$ \\
\hline
\end{tabular}

Figure $5 \mathrm{a}, \mathrm{b}$ present, respectively, the distribution of the mean confidence factors obtained from the evaluation of the parameters that compose the $\mathrm{I}_{\mathrm{V}}$ and the global assessment of the 91 pilot-buildings.

As can be seen in Figure 5a, the mean CF E/M is the one that has been used more often, having been assigned to parameters P2, P5, and P7 (position into the aggregate, irregularities in height, and short columns). The second confident factor with higher expression is the E-, with parameters P6 and P8 (soft-story mechanisms and other structural elements). Finally, due to the lack of information 
on the type of soil, parameter P1, which evaluates the building location, is the one that presents the lowest mean confidence factor $(\mathrm{A}+$ ). Figure $5 \mathrm{~b}$ presents the mean confidence factor associated with the building's classification, i.e., corresponding to the average of the confidence factor attributed to each parameter assessed. The average confidence factor $\mathrm{E} / \mathrm{M}$ is the one that has the most expression with 24 buildings (about $22 \%$ of the total sample), followed by the CF M+ with 23 buildings (about $21 \%$ ). From this analysis, it is further possible to observe that there are five buildings with an average confidence factor lower than M/B. The average CF B- has three buildings (about 3\%), whereas the average $\mathrm{CFs} \mathrm{B}$ and $\mathrm{B}+$ present one building each (about $1 \%$ ).

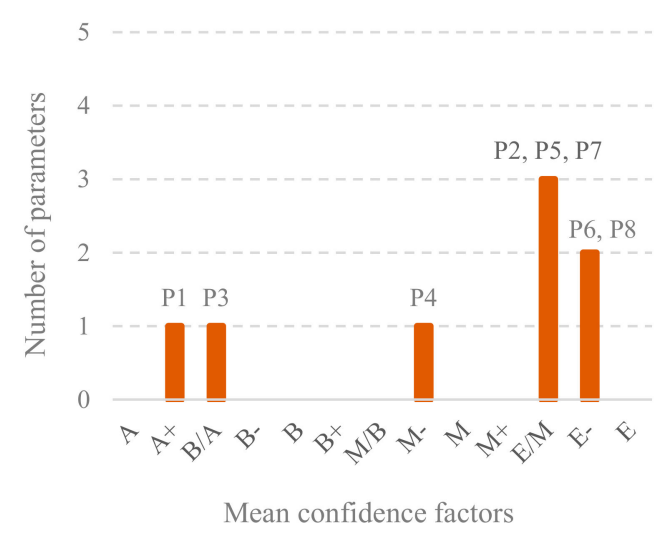

(a)

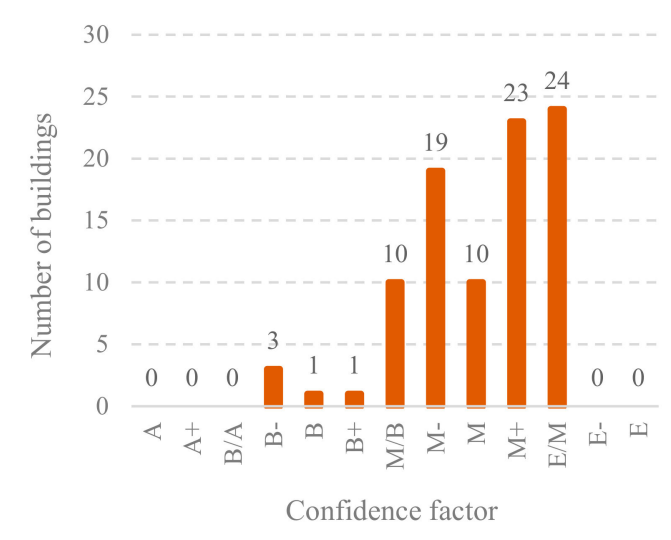

(b)

Figure 5. Distribution of the confidence factor associated with the evaluation parameters (a) and the global assessment (b).

\subsection{Damage Estimation and Construction of Vulnerability Curves}

After the analysis of the vulnerability index for the RC buildings, it is essential to estimate the mean damage grade, $\mu_{D}$, associated with each one of them. The attribution of the mean damage grade was carried out individually by a group of experts, and have the average value taken from their evaluations assumed as final. Following this procedure, it was possible to get a more reliable value to obtain the damage expression. As so far there are no curves proposed and validated for RC buildings able to correlate the severity of the action with a damage grade defined according to the European Macroseismic Scale EMS-98 [9], the information collected for the 91 pilot-buildings was used for this purpose. Thus, a new correlation curve between the vulnerability index, the macroseismic intensity registered in situ, and the observed damage was then obtained.

Figure 6 presents the variations on the mean damage grade, $\mu_{D}$, obtained for each building, organized by macroseismic intensity. It is worth noting that, due to the reduced number of buildings assed for intensities $I_{E M S-98}=\mathrm{V}$ and $I_{E M S-98}=\mathrm{VI}$, such intensities were excluded from the sample subsequently used for constructing the vulnerability curves. In consequence to that, the estimation of cumulative losses due to frequent, low-intensity earthquakes in a given timeframe, is limited and therefore further efforts should be made to enlarge this database, mainly for intensities $I_{E M S-98}=\mathrm{V}$ and $I_{E M S-98}=$ VI.

From the analysis of Figure 6, it can be noted that, for a seismic scenario with an intensity equal or higher than VIII, most of the buildings considered in this analysis present mean damage grades of $D_{k}=4$ and $D_{k}=5$, which means severe damage or collapse.

The methodology used in the elaboration of the seismic vulnerability study is an adapted version of the approach proposed by [15]. In that work, the authors have elaborated a vulnerability index for each building typology based on five values representative of the vulnerability: $V_{I}^{*}, V_{I}^{-}, V_{I}^{+}, V_{\text {Imin }}$, and $V_{\text {Imax }}$, where $\mathrm{VI}^{*}$ corresponds to the most probable value for a specific building typology, and the 
values of $V_{I-} / V_{I+}$ and $V_{I \min } / V_{\text {Imax }}$ refer respectively to the probable and less probable vulnerability index ranges for the considered RC typologies, see Table 8.
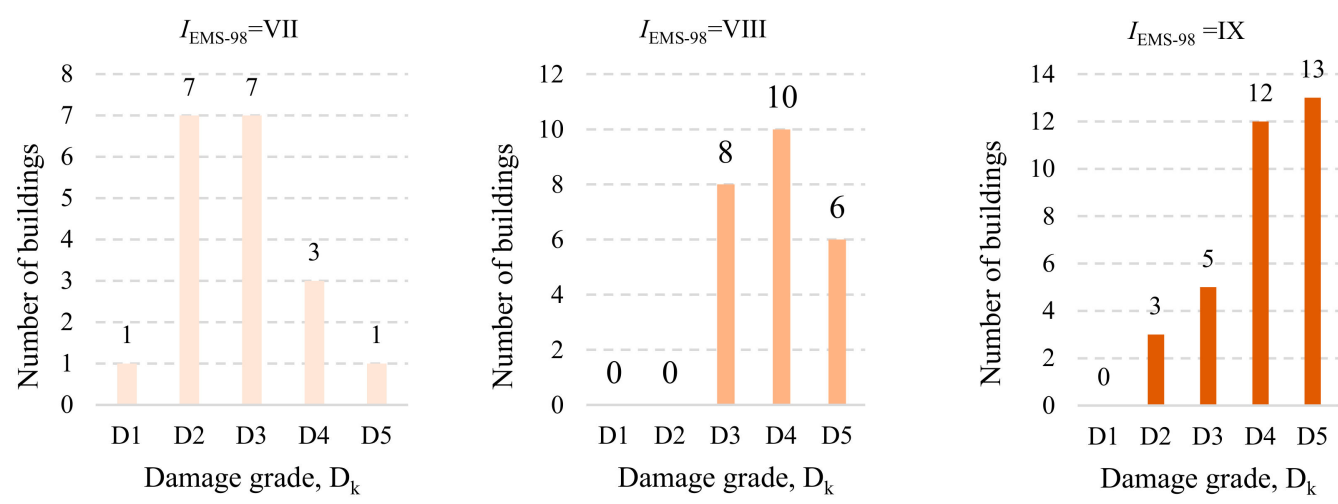

Figure 6. Distribution of the damage grades for different macroseismic scenarios.

Table 8. Vulnerability indexes for each reinforced concrete building typology, adapted from [16].

\begin{tabular}{rlccccc}
\hline & Building Typology & \multicolumn{5}{c}{ Vulnerability Class } \\
\cline { 3 - 7 } & $\begin{array}{c}\text { Frame in RC without Earthquake } \\
\text { Resistant Design (ERD) - RC1 }\end{array}$ & 0.3 & 0.49 & 0.644 & 0.8 & 1.02 \\
\hline \multirow{2}{*}{$\begin{array}{c}\text { Reinforced } \\
\text { Concrete } \\
(\text { RC })\end{array}$} & Frame in RC moderate ERD - RC2 & 0.14 & 0.33 & 0.484 & 0.64 & 0.806 \\
\cline { 2 - 7 } & Frame in R.C high ERD - RC3 & -0.02 & 0.17 & 0.324 & 0.48 & 0.7 \\
\cline { 2 - 7 } & Shear walls without ERD - RC4 & 0.3 & 0.367 & 0.544 & 0.67 & 0.86 \\
\cline { 2 - 7 } & Shear walls moderate ERD - RC5 & 0.14 & 0.21 & 0.384 & 0.51 & 0.7 \\
\cline { 2 - 7 } & Shear walls high ERD - RC6 & -0.02 & 0.047 & 0.224 & 0.35 & 0.54 \\
\hline
\end{tabular}

A vulnerability index, $\mathrm{V}$, ranging between 0 and 1 is associated to each typology, describing it from A to $\mathrm{F}$, where $\mathrm{A}$ is the seismically most resistant typology, and $\mathrm{F}$ corresponds to the less resistant one.

As it is presented in Equation (2), a new vulnerability function that relates mean damage grades, $\mu_{D}$, and macroseismic intensities, IEMS-98 [9], adjusted to RC building typology was obtained from the vulnerability index value V. Such formulation is based on the same mathematical expression of previous vulnerability curves proposed for other building typologies (namely for unreinforced masonry building) and can assume values between 0 and 5 :

$$
\mu_{D}=a \times\left[1+\tanh \left(\frac{x+b \times V-11.6}{Q}\right)\right]
$$

This mean damage grade, $\mu_{D}$, depends on the variables a and $\mathrm{b}$, which were obtained through successive calibrations in order to find the optimum value for variables: $x$, which represents the seismic intensity; $V$, the vulnerability index; and $Q$, a ductility coefficient factor which depends on the structural typology. Based on the vulnerability index $V$, it is then possible to calculate the probabilities of exceeding each mean damage grade proposed in the EMS-98 (D1 to D5) in the function of the macroseismic intensity. The value of $V$ is obtained through Equation (3), where $d$ and $e$ are dependent on the building typology and $I_{v}$ is the vulnerability index obtained from the analysis of each building:

$$
V=d+I_{v} \times e
$$

Resorting to Equation (3) and relating the lower and upper values of the vulnerability classes given in Table $8, V_{\text {Imin }}$, and $V_{\text {Imax }}$, respectively with the lower and the upper value of the $\mathrm{I}_{\mathrm{V}}$ range ( 0 and 100), 
it is then possible to compute the unknowns $e$ and $d(e=0.0104$ and $d=-002)$, in Equation (4). It should be noted that this hypothesis is based on the assumption that, in this way, all the types of reinforced concrete buildings presented in Table 8 are considered:

$$
V=-0.02+I_{v} \times 0.0104
$$

The curve fitting tool available in Matlab ${ }^{\circledR}$ was applied to Equation (5) in order to obtain the damage expression based on the mean damage grade obtained for each of the 91 buildings evaluated. Using as a fixed value, the mean vulnerability index value $\left(I_{v, \text { mean }}=38.73\right)$, and assuming that the curve has a development of hyperbolic shape, a new expression usable to estimate the mean damage grade $\left(\mu_{D}\right)$ was obtained, Equation (6). The values resulting from variables a and $\mathrm{b}$ were respectively 2.839 and 10.79. The coefficient of ductility, $Q$, assumed in this work as 5.0, was selected following what is defined in international guidelines and the Portuguese code for the design of RC structures "Code for Design of Reinforced and Prestressed Concrete Structures (REBAP)" [17]:

$$
\mu_{D}=2.839 \times\left[1+\tanh \left(\frac{I+10.79 \times V-11.6}{5}\right)\right]
$$

Figure 7 shows the comparison between the results obtained and the analytical expressions given by Equation (5), considering the $I_{v, \text { mean }}=38.73$ and the own damage grade observed for each one of these buildings. Additionally, three yellow dots, representing the mean values obtained from the $I_{v}$ for each intensity, were also included.

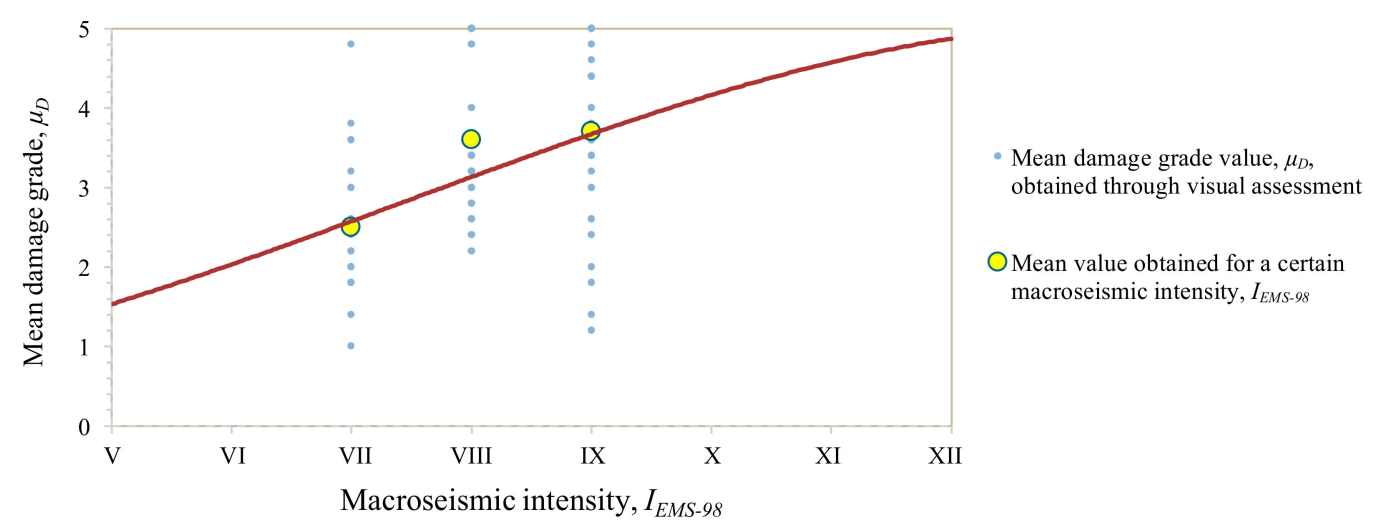

Figure 7. Best curve fit to the average values of the assessed buildings with damage.

Finally, Figure 8 presents the vulnerability curves obtained with the average value of the vulnerability index, with the addition and subtraction, single and double, of the standard deviation value obtained from the sample of 91 buildings. The analysis of the curves shows that the variation range of the degree of damage for each seismic intensity is relevant.

Based on the vulnerability curves presented in Figure 8, it is possible to observe that a building with a vulnerability index value higher than 51 , a common value either for irregular buildings or with structural issues related with probable soft-stories or short columns, can present a mean damage grade between 2 and 3 for a seismic intensity of $\mathrm{V}$, which means that it can present unneglectable structural damages. For seismic intensities between VIII and IX, the expectable mean damage grade can be 4 or higher, meaning that significant structural damages, or even collapse, may occur. For a regular building without particular structural issues, the vulnerability index can be around 25 , which represent a mean damage grade rounding 1 for a seismic intensity of $\mathrm{V}$, and a mean damage grade lower than 3 (some structural damages without collapse) for a macroseismic intensity between VIII and IX. 


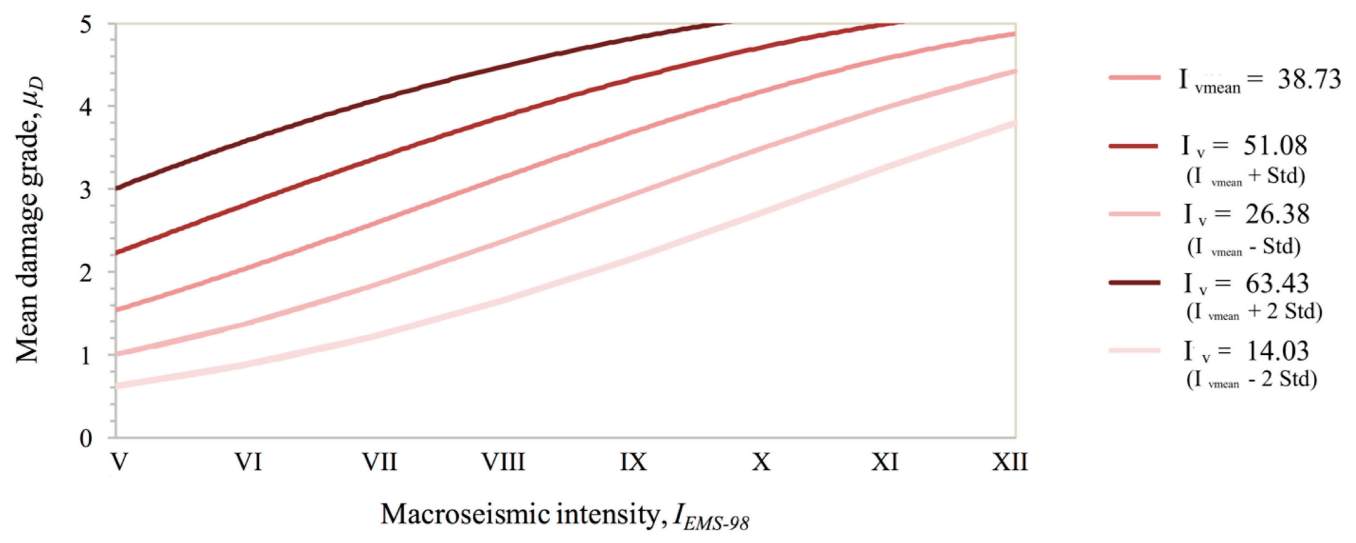

Figure 8. Vulnerability curves for Reinforced Concrete buildings.

\section{Application to Faro City Centre}

\subsection{Brief Historical Background}

The city of Faro is the capital of the Algarve region, with around 60,000 inhabitants. Initially called Ossónoba, in Portuguese "salt warehouse", it has undergone numerous changes over the centuries. In the middle of the 16th century, following the history of the city, Faro was organized with its current form $[18,19]$. In 1755 , the city was extremely affected by the Great Lisbon Earthquake. The vast majority of the most notable buildings existing in the old urban core of the city were thus built after that [19]. In 1969, another strong earthquake, with a magnitude of approximately 7.3 on the Richter scale, affected the entire region, including Faro. Many reports refer that the earth and adobe buildings collapsed, and the traditional stone masonry buildings suffered considerable damage due to the insufficient seismic capacity of the structures [20]. Modern masonry and RC buildings suffered minor damage.

\subsection{Vulnerability Index Results}

The presented methodology was applied to the 166 identified buildings through visual inspections and access to building data. The application resulted in an average vulnerability index, $I_{v}$, of 29.36. The associated standard deviation, $\sigma_{I v}$, is approximately 13.40 . About $77 \%$ of the assessed buildings present a vulnerability index of less than 40 , and only $5 \%$ of the buildings have an index greater than 50. The maximum and minimum vulnerability index obtained is 66.30 and 3.33, respectively. Figure 9 shows the spatial distribution of vulnerability indices of the RC buildings evaluated. Through the color scale, it is possible to notice that most buildings have a relatively low vulnerability index. The higher vulnerability index value is associated with a building with four upper floors of residential use, and a commercial area at the ground floor level. Besides, it has a difference of heights between floors and a rooftop indentation. Due to these most penalizing factors, the vulnerability index results in the highest value between the assessed buildings. The lowest determined vulnerability index is 3.33 and corresponds to a building only with two floors, with no commercial area on the ground floor and no irregularities, which leads to a low vulnerability index value. 


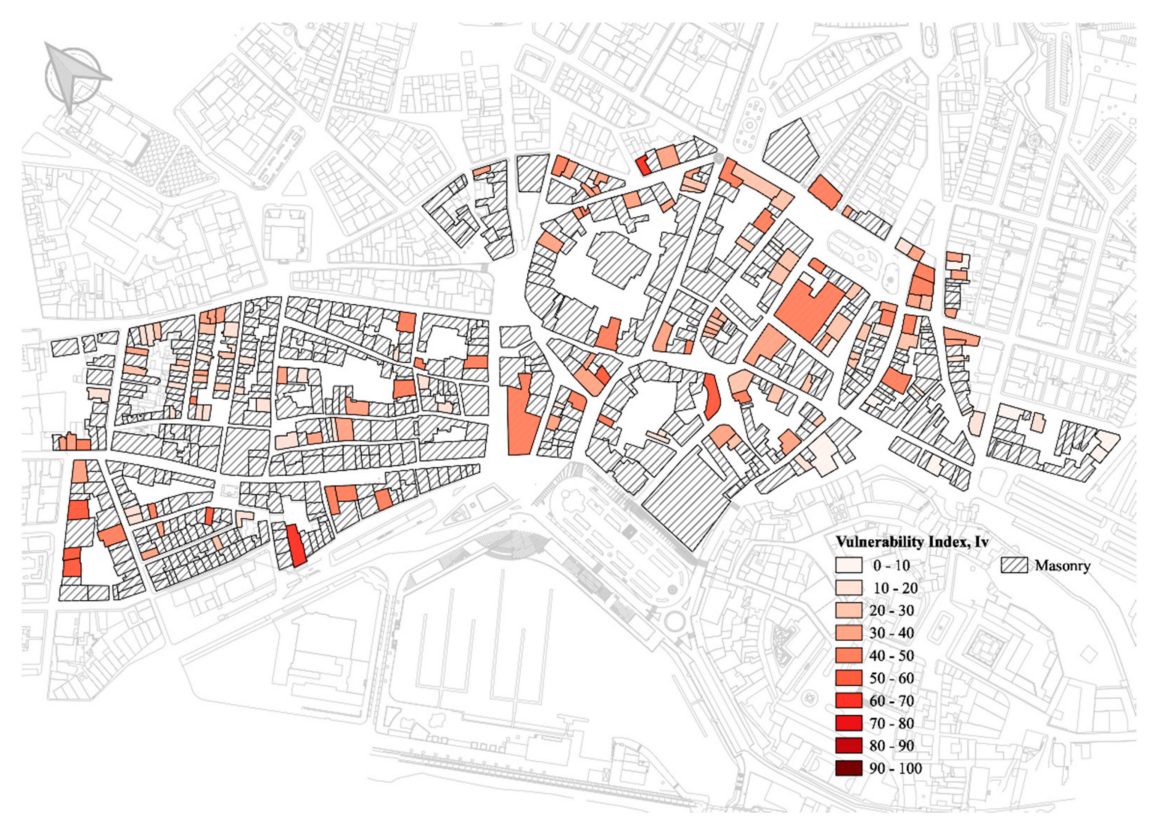

Figure 9. Mapping of the vulnerability index values.

\subsection{Damage Estimation}

After obtaining the vulnerability index of each building, the damage grade, $\mu_{D}$, was estimated for each structure and different macroseismic intensities, $I_{E M S-98}$, resorting to Equation (5). For seismic intensities between $\mathrm{V}$ to $\mathrm{VI}$, a large percentage of buildings are expected to suffer a level of damage between D1 and D3, i.e., minor (non-structural) to moderate structural damage, whereas, at higher intensities (between VII and VIII), level of damage may attain D3 to D5. Respectively for macroseismic intensities of IX and X, about $20 \%$ and $72 \%$ of the buildings may collapse. The results for the original state of the buildings are presented later in Section 4.2. In the next section, it will be presented and discussed the effect that the adoption of a possible strengthening action may have in the reduction of the seismic vulnerability of the buildings stock and, in consequence of that, of their expectable level of damage.

\section{Evaluation of the Adoption of a Seismic Strengthening Solution}

According to the seismic vulnerability assessment method described in the previous section, the buildings with the highest vulnerability index will potentially suffer from eventual soft-story mechanisms. One way to avoid this failure mechanism could be obtained by reducing the possibility of the occurrence of the mechanism, introducing a strengthening solution designed specifically for the purpose, such as the installation of steel braces with energy dissipation device associated (SB-EDD), which can increase stiffness and the damping of the building and, consequently, reduce the deformation demands. This strengthening technique was based on the solution studied in detail for other buildings by Furtado et al. [21] and makes it possible to correct the soft-story mechanism, with lightweight solutions that can fit into the architecture of the buildings. This solution was therefore virtually implemented in the 101 buildings that, according to the previous vulnerability results, presented this fragility (i.e., all those buildings that were previously evaluated with a vulnerability class D in Parameter P6, which is related to the soft-story mechanism). Methodologically, this is done by changing the original classification of parameter $\mathrm{P} 6$ from $\mathrm{D}$ to class $\mathrm{A}$.

\subsection{Reassessment of the Vulnerability Index: Parameter P6}

The change introduced in the vulnerability class of parameter P6 naturally leads to a reduction in the vulnerability index. Thus, an average $I_{v}$ of 19.18 and a standard deviation, $\sigma_{I v}$, of 8.94 was 
obtained, i.e., $I_{v}$ and $\sigma_{I V}$ have a decrease of approximately $35 \%$ and $33 \%$, respectively, from the initial value. Figure 10 shows the histogram of the distribution of values of vulnerability indices, pre- and post-strengthening. This comparison shows that the vulnerability index decreased significantly. In fact, with the strengthening, about $98 \%$ of buildings have a vulnerability class lower than 40 , while only $2 \%$ have an $I_{V}$ between 40 and 50 . The maximum and minimum vulnerability index is 49.6 and 3.33 , respectively.

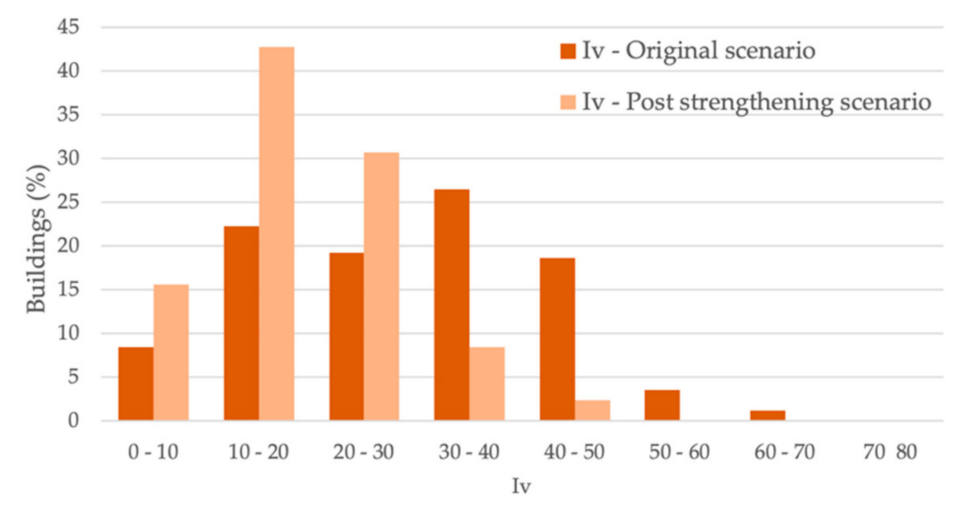

Figure 10. Comparison of the vulnerability index pre- and post-strengthening.

\subsection{New Damage Estimation}

After obtaining the new vulnerability indices for each building, the associated mean damage grades were re-estimated using the procedure presented earlier in Section 2.3. Figure 11 shows the vulnerability curves referring to the original and the strengthened scenarios, plotted for the characteristic values of the vulnerability index distributions: $I_{v, \text { mean }}, I_{v \text {, mean }}+\sigma_{I v}$, $I_{v, \text { mean }}-\sigma_{I v}, I_{v \text {, mean }}+$ $2 \sigma_{I v}$, and $I_{v, \text { mean }}-2 \sigma_{I v}$.

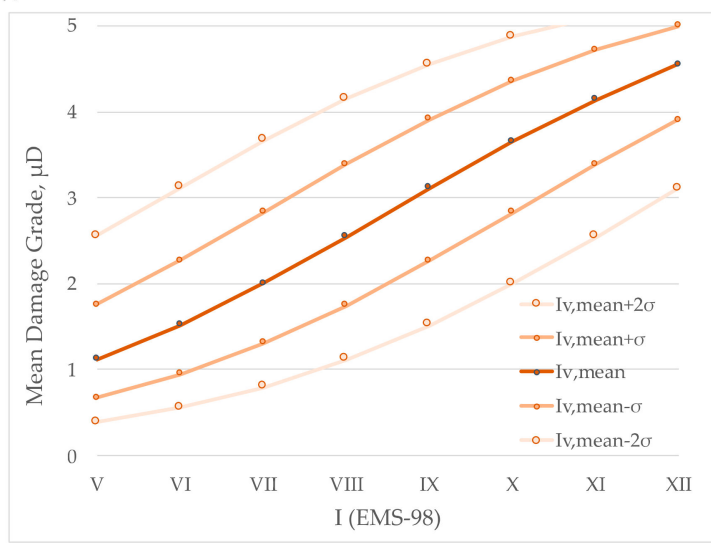

(a) original scenario

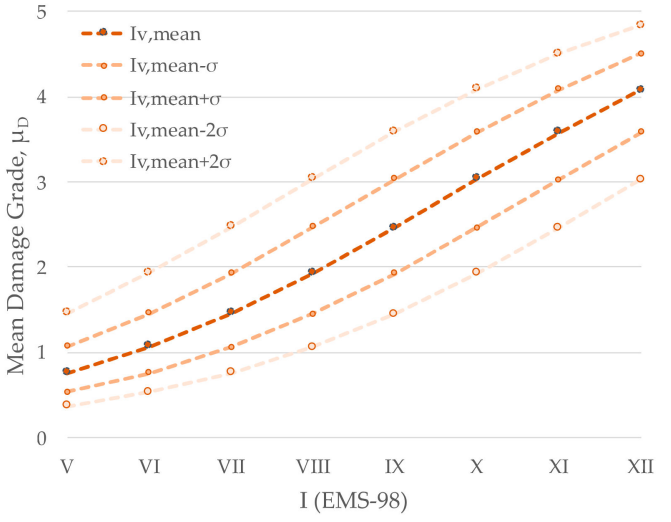

(b) strengthened scenario

Figure 11. Vulnerability curves for the original (a) and the strengthened (b) scenarios.

Furthermore, Figure 12 presents the damage grade distribution, pre- and post-strengthening, for different macroseismic intensities. As expected, after strengthening the most vulnerable structures, the overall level of damage decreases. Such a decrease is particularly expressive for the macroseismic intensity XII. In this case, the percentage of buildings with a damage grade D5 is much lower than the initial values, which means that the number of collapsing buildings has decreased significantly (from more than $70 \%$ of collapsed buildings to less than $10 \%$ ). 


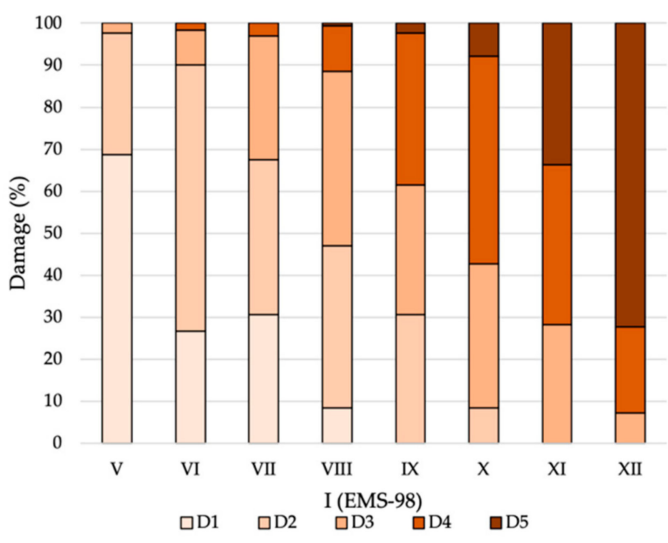

(a) original scenario

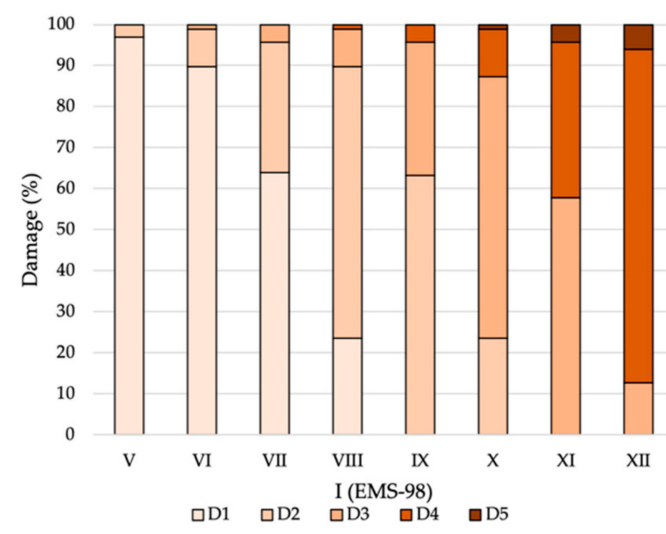

(b) post-strengthening

Figure 12. Damage distribution by the different macroseismic intensities.

Figure 13 shows the damage scenarios for seismic events characterized by macroseismic intensities, $I_{E M S-98}$, between VII and X. From the observation of the figures, it is possible to observe a significant difference in the color scale for the same macroseismic intensity after application of the seismic strengthening action.
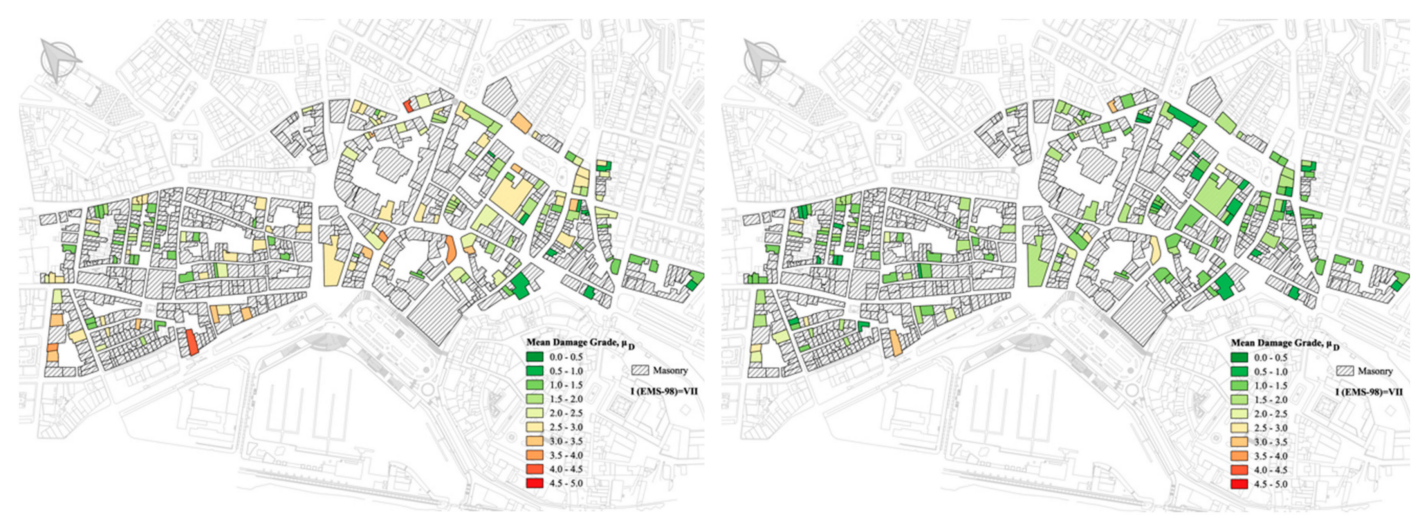

(a) $I_{E M S-98}=$ VII
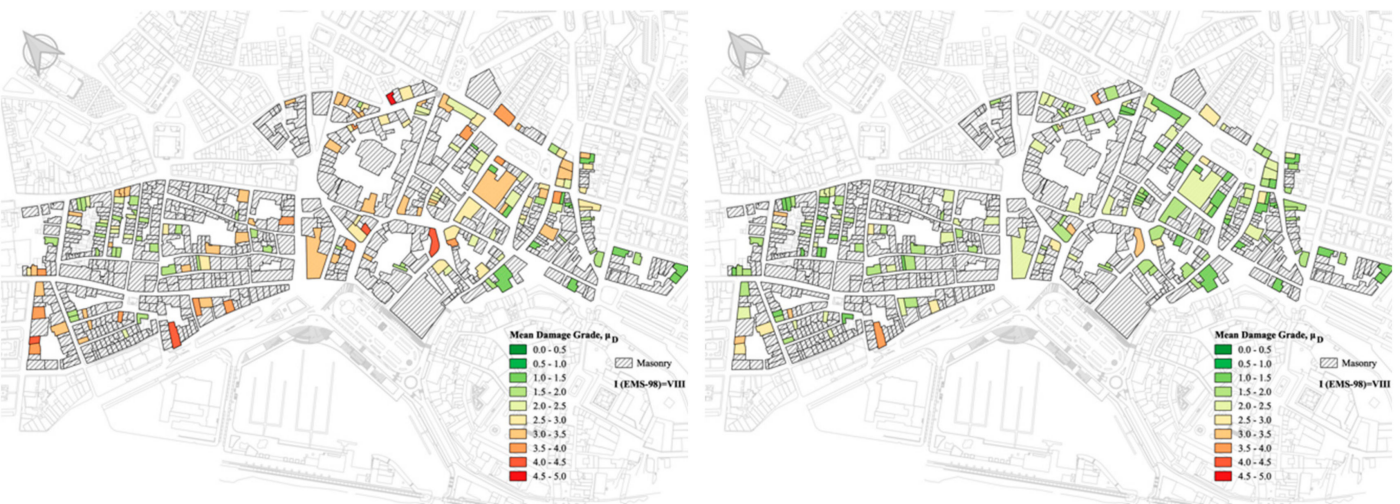

(b) $I_{\text {EMS-98 }}=\mathrm{VIII}$

Figure 13. Cont. 


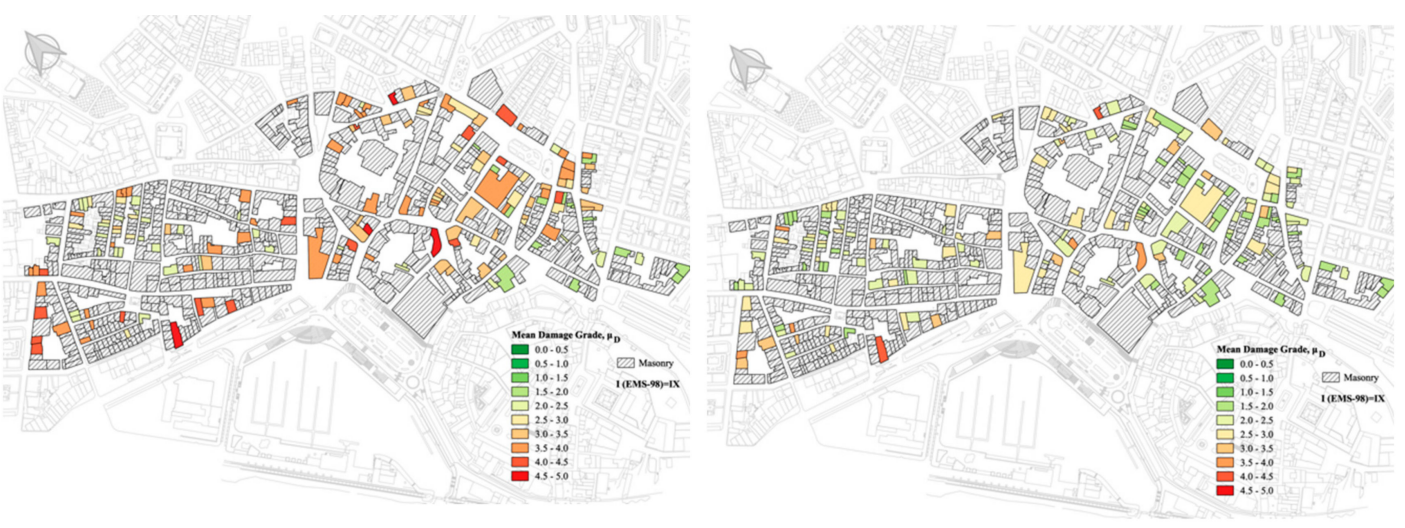

(c) $I_{E M S-98}=\mathrm{IX}$

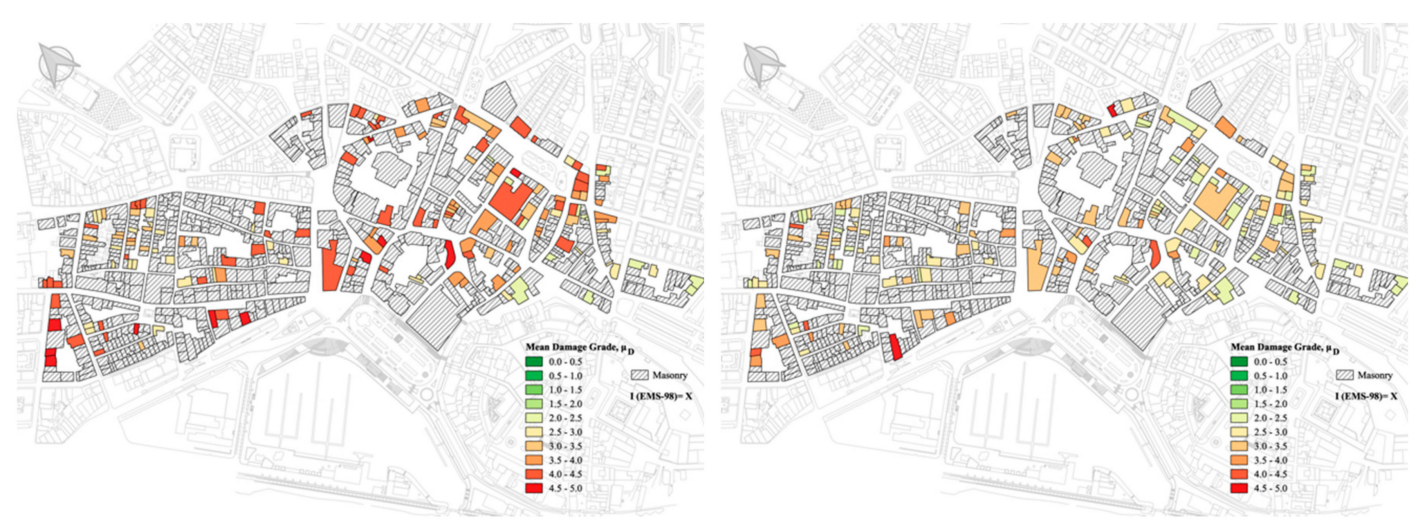

(d) $I_{E M S-98}=\mathrm{X}$

Figure 13. Original and post-strengthening damage scenarios.

\subsection{Construction of Fragility Curves}

Fragility curves are another way to represent the expected damage by defining the probability of exceeding certain degrees. These are obtained directly from the cumulative beta density function for a given vulnerability index value. Fragility curves define a relationship between seismic intensity and damage in terms of a continuous probability function, thereby expressing the conditional cumulative probability of reaching or exceeding a given damage state. The discrete probabilities, $P\left(D_{K}=d\right)$, are obtained by the difference of the cumulative probabilities, $P D\left[D_{i} \geq d\right]$, as represented in Equation (6): $P\left(D_{K}=d\right)=P D\left[D_{k} \geq d\right]-P D\left[D_{K+1} \geq d\right]$

$$
P\left(D_{K}=d\right)=P D\left[D_{K} \geq d\right]-P D\left[D_{K+1} \geq d\right]
$$

Figure 14 shows the fragility curves corresponding respectively to the original and the strengthened scenario. As can be seen from Figure 14 and as expected, after strengthening the critical buildings, the probability of exceeding the degree of damage decreases noticeably. By way of example, the probability of exceeding the degree of damage D3 for an earthquake of intensity VIII decreased by about $30 \%$. 


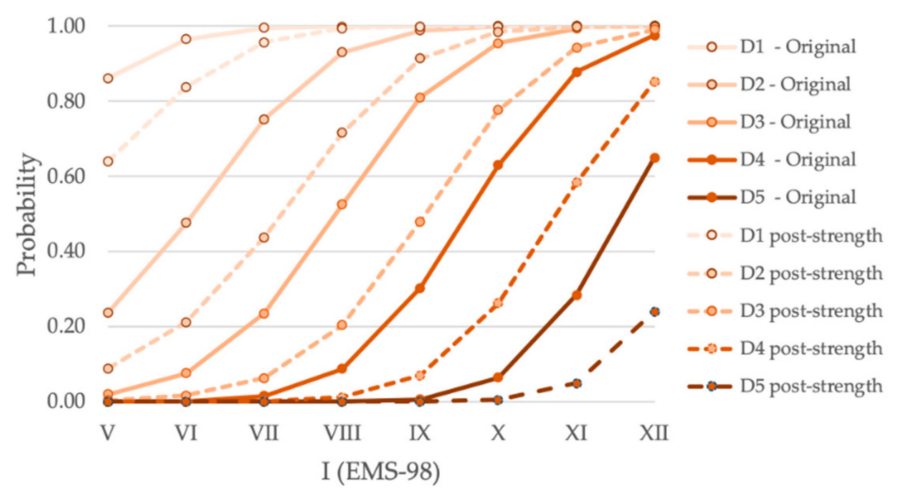

Figure 14. Comparison of fragility curves for the original and the strengthened scenario, i.e., for $I_{v}=29.36$ and $I_{v}=19.18$.

\subsection{Economic losses and Estimation of Repair Costs}

This section presents a cost-benefit analysis of the strengthening solution considered above and the relative cost used is obtained by the ratio of the estimated cost of the strengthening to the total cost of building, as represented in Equation (7):

$$
\text { Relative cost }=\frac{\text { Total cost of strengthening } \times \text { Area in plan }}{\text { Construction area } \times \text { Construction cost }} .
$$

Given that the reinforcement of the structures is an intervention made only on the ground floor from energy dissipators [21], a total cost of strengthening was estimated as $80 € / \mathrm{m}^{2}$, based on the values proposed by Furtado et al. [21]. For the construction cost, the average asset value of the buildings was taken into account. Thus, a value of $750 € / \mathrm{m}^{2}$ was assumed based on the average value attributed by the tax authorities to properties in the region. The area in plan refers to the area in plan of the building, and the construction area is the area in plan multiplied by the number of stories. Figure 15 shows the distribution of the relative cost of repair for the non-strengthened buildings and to the strengthened ones.

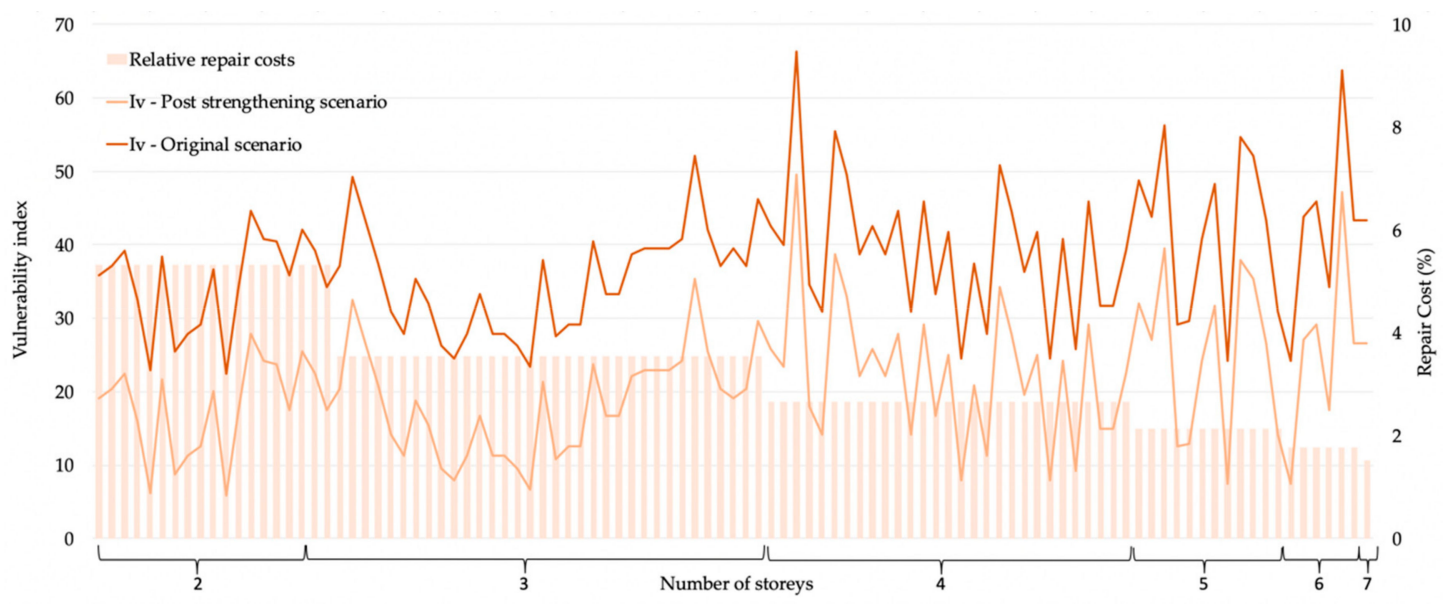

Figure 15. Relative costs of repair, pre-, and post-strengthening.

To observe its reduction after the intervention, the vulnerability index of the 101 buildings strengthened is also presented. In order to facilitate analysis, the buildings are organized by the number of floors. Figure 15 shows that the relative cost varies between $1.5 \%$ and $5.3 \%$. Since the intervention was planned to be implemented only in the ground-stories, as expected, the taller buildings present lower relative cost when compared with the smaller ones. Thus, the relationship between the total cost 
of reinforcement and the total value of construction has higher values in buildings with fewer floors. In buildings with 6 or 7 floors, the relative cost is less than $2 \%$ of the construction value.

After obtaining the average degree of damage, the data can be interpreted using an economic index by applying the ratio of repair to replacement cost [22]. The correlation between degrees of damage and repair and reconstruction costs is obtained by analyzing and processing post-earthquake data [23]. Resorting to Equation (8), it is possible to estimate the repair costs for a given macroseismic intensity earthquake I, by the product of the conditioned probability of the repair cost, $P\left[R \backslash D_{K}\right]$ and the conditioned probability of the damage for a specific building vulnerability and seismic intensity $\mathrm{P}$ $\left[D_{K} \backslash I_{v}, I\right][11]:$

$$
P[R \backslash I]=\sum_{D_{K}=1}^{5} \sum_{I_{v}=1}^{100} P\left[R \backslash D_{K}\right] \times P\left[R \backslash I_{v}, I\right]
$$

The associated repair cost was estimated from the mean values of pre-reinforcement and post-reinforcement vulnerability indices, $I_{v, \text { mean }}=29.36, I_{v, \text { mean }}=19.18$, respectively. Figure 16 presents the estimated repair cost for the different vulnerability indices for the entire study area as a function of seismic intensity. Moreover, the relationship between the initially estimated degree of damage $\left(\mu_{D}\right)$ and the degree of damage after strengthening $\left(\mu_{\text {Dint }}\right)$ is also represented in the figure by the black slashed line.

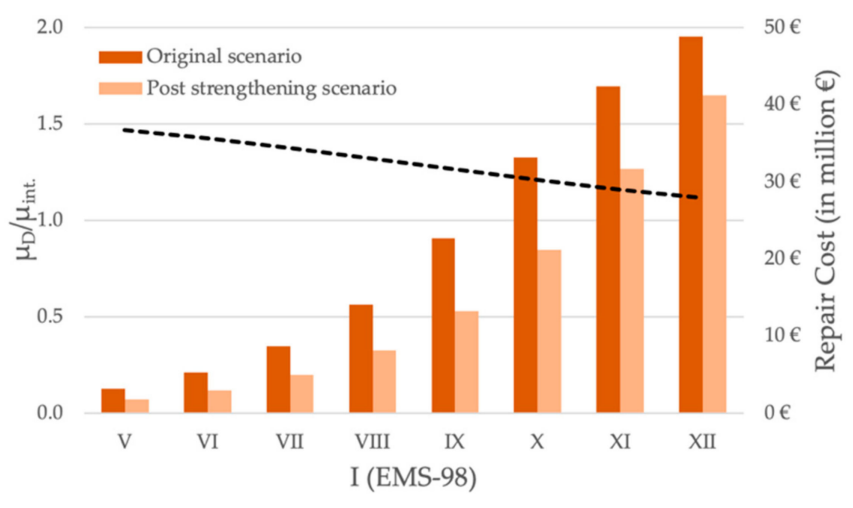

Figure 16. Estimated repair cost for different vulnerability indices.

As can be seen in Figure 16, the ratio of pre-strengthening and post- strengthening damage degrees decrease as the intensity increases. After strengthening the conditioning buildings, the estimated repair costs are significantly reduced. Intensity $X$ deserves particular attention, since, besides it corresponds to the maximum historical intensity recorded in the city of Faro, it presents the most considerable difference in terms of repair cost between the original and the strengthened buildings.

Moreover, as represented in Equation (9), the economic balance is obtained by the difference of the cost of repair without strengthening, $C R_{\text {Pre-strengthening, }}$ and the total cost of repair considering strengthening, which is in turn obtained by summing the cost of repair with strengthening, $\mathrm{CR}_{\text {Post-strengthening, }}$ and the cost of the strengthening itself, $\mathrm{C}_{\text {Strengthening: }}$

$$
\text { Economic Balance }=C R_{\text {Pre-strengthening }}-\left(\mathrm{CR}_{\text {Post-strengthening }}+\mathrm{C}_{\text {strengthening }}\right) \text {. }
$$

Figure 17 presents the results of the economic balance of the entire study area as a function of macroseismic intensity. 


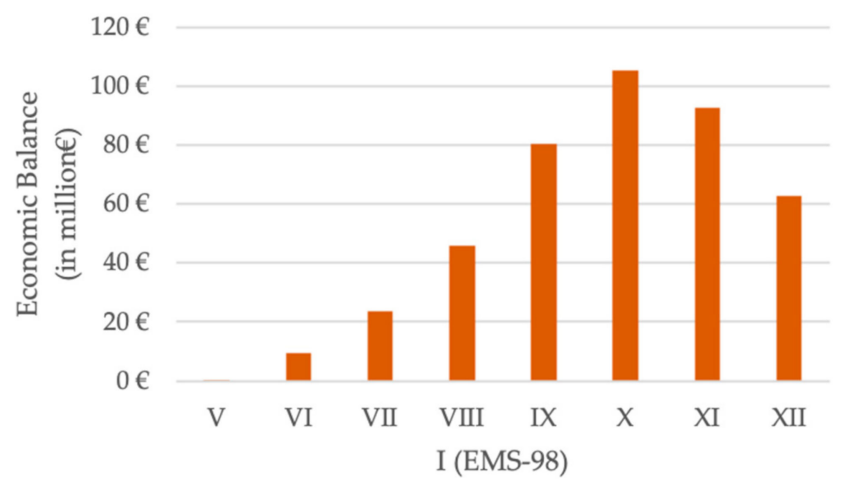

Figure 17. Economic balance for the whole study area.

As can be seen from Figure 17, in economic terms, the most favorable balance is obtained for the macroseismic intensity $\mathrm{X}$. Moreover, it is also possible to observe that the strengthening solution analyzed in this work is efficient and economically viable for the whole intensity spectrum presented in Figure 16.

\section{Conclusions}

From the obtained results discussed in the presented paper, it is possible to draw some important conclusions. At first, from the analysis of the seismic vulnerability index, it was possible to identify the parameters with more significant influence in the behavior of RC buildings under seismic loads, allowing to calibrate the weights associated with the evaluation parameters that compose the $I_{v}$. Regarding the mean degree of confidence of each parameter, the analysis allowed to observe which parameters should be further studied in order to improve and control the quality of the vulnerability index results. The development and calibration of an equation that characterizes the medium damage grade, allowing for the estimation of the level of damage in an RC building when subjected to a certain seismic intensity, is also a very relevant output of this work. In general, when a building has a high vulnerability index, this means that it is more probable to suffer higher levels of damage, even if subjected to low seismic intensities.

From the exposed, it is possible to say that this simplified method can be a valuable tool for performing large-scale seismic vulnerability assessments of RC buildings, particularly in view of the development and implementation of risk management plans and mitigation actions.

Regarding the application to the city of Faro, some main conclusions can also be drawn. Firstly, it is worth noting that this methodology may lead to possible inaccuracies due to the omission of some information for parameter classification. However, it has proved to be very efficient on the identification of the most vulnerable RC buildings, allowed to develop comprehensive vulnerability and damage scenarios. In this particular case, most of the buildings studied in this work present commercial areas on the ground-floor level, which enhances the potential development of soft-story mechanisms. In order to mitigate this structural fragility, the feasibility of adopting a strengthening intervention based on energy dissipators was analyzed herein. With the obtained information, additional studies could be performed aimed at estimating different types of losses, namely human and economic losses, as well as to quantify the resources/time needed to recovery the functionality of the buildings. Among other relevant applications, this kind of output can be effectively used by stakeholders to prioritize interventions and to define disaster prevention and mitigation policies [24]. From the economic analysis carried out, it was possible to conclude that, besides being a relatively low impacting intervention (as it is performed only at ground level), it is a very cost-effective intervention, resulting in a very interesting cost-benefit ratio for the whole spectrum of seismic intensities considered.

Author Contributions: Conceptualization, T.M.F., H.R. and R.V.; Methodology, T.M.F., H.R. and R.V.; Writing-original draft, T.M.F., H.R. and R.V. All authors contributed to every part of the research described in this paper. All authors have read and agreed to the published version of the manuscript. 
Funding: This research received no external funding.

Conflicts of Interest: The authors declare no conflict of interest.

\section{References}

1. Vicente, R.; Ferreira, T.M.; Maio, R.; Costa, A.A.; Estêvão, J.; Varum, H.; Oliveira, C.S. Metodologia de avaliação da vulnerabilidade sísmica: Calibração e validação macrossísmica. In $5^{\text {as }}$ Jornadas Portuguesas de Engenharia de Estruturas (JPEE); National Laboratory of Civil Engineering (LNEC): Lisbon, Portugal, 2014.

2. Ferreira, T.M. Avaliação da Vulnerabilidade Sísmica de Núcleos Urbanos Antigos. APLICAÇÃO Ao Núcleo Urbano Antigo Do Seixal. Ph.D. Thesis, Faulty of Engineering of the University of Oporto, Porto, Portugal, 2010.

3. Bal, I.; Gulay, F.; Tezcan, S. A new approach for the preliminary seismic assessment of RC buildings: P25 Scoring Method. In Proceeding of the 14th World Conference on Earthquake Engineering (ECEE), Beijing, China, 12-17 October 2008.

4. ATC-21. Rapid Visual Screening of Buildings for Potential Seismic Hazards: A Handbook. In Rapid Visual Screening of Buildings for Potential Seismic Hazards: A Handbook; Applied Technology Council: Redwood City, CA, USA, 1988.

5. GNDT-SSN. Scheda di Esposizione e Vulnerabilità e di Rilevamento Danni di Primo e Secondo livello (murata e cemento armato); Gruppo Nazionale per la Difesa dai Terremoti: Rome, Italy, 1994.

6. Hirosawa, M.; Sugano, S.; Kaminosono, T. Seismic evaluation method and restoration techniques for existing and damaged buildings developed in Japan. In Retrofitting and Restration of Buildings in Japan; International Ministry of Construction: Tokyo, Japan, 1993; pp. 1-69.

7. Yakut, A.; Erberik, A.; Akkar, S.; Sucuoglu, H. Rapid Seismic Assessment Procedures for Turkish Building. In Seismic Evaluation and Rehabilitation of Structures; Springer: Berlin, Germany, 2012; pp. 15-35.

8. Rai, D.C. A generalized method for seismic evaluation of existing buildings. Curr. Sci. 2008, 94, 363-370.

9. Grünthal, G. Cahiers du Centre Européen de Géodynamique et Séismologie: Volume 15-European Macroseismic Scale 1998 (EMS-98). Eur. Cent. Geodyn. Seismol. Luxemb. 1998.

10. Vicente, R.; Parodi, S.; Lagomarsino, S.; Varum, H.; Mendes da Silva, J.A.R. Seismic vulnerability and risk assessment: Case study of the historic city centre of Coimbra, Portugal. Bull. Earthq. Eng. 2011, 9, 1067-1096. [CrossRef]

11. Ferreira, T.M.; Vicente, R.; Mendes da Silva, J.A.R.; Varum, H.; Costa, A. Seismic vulnerability assessment of historical urban centres: Case study of the old city centre in Seixal, Portugal. Bull. Earthq. Eng. 2013, 11, 1753-1773. [CrossRef]

12. Ferreira, T.M.; Vicente, R.; Varum,H. Seismic vulnerability assessment of masonry facade walls: Development, application and validation of a new scoring method. Struct. Eng. Mech. 2014, 50, 541-561. [CrossRef]

13. Vicente, R. Estratégias e Metodologias para Intervenções de Reabilitação Urbana. Avaliação da Vulnerabilidade e do Rísco Sísmico do Edificado da Baixa de Coimbra. Ph.D. Thesis, Civil Engineering, University of Aveiro, Aveiro, Portugal, 2008.

14. Silva, J. Metodologia de Avaliação da Vulnerabilidade Sísmica de Edifícios em Betão Armado. Master's Thesis, Civil Engineering, University of Aveiro, Aveiro, Portugal, 2015.

15. Lagomarsino, S.; Giovinazzi, S. Macroseismic and mechanical models for the vulnerability and damage assessment of current buildings. Bull. Earthq. Eng. 2006, 4, 415-443. [CrossRef]

16. Giovinazzi, S. The Vulnerability Assessment and the Damage Scenario in Seismic Risk Analysis. Ph.D. Thesis, University of Florence, Florence, Italy, 2005.

17. REBAP. Regulamento de Estruturas de Betão Armado e Pré-EsforçAdo, Decree Law n 349-C/83 of July 30; REBAP: Lisbon, Portugal, 1983; p. 211.

18. Diniz, M.B. Arquitectura Civil em Faro Após o Terramoto de 1755; Câmara Municipal de Faro: Faro, Portugal, 1981.

19. Maio, R.; Ferreira, T.M.; Vicente, R. The morphology of old urban centres: Architectural and constructive survey of Bairro Ribeirinho of Faro, Portugal. Conserv. Patrim. 2015, 21, 5-24. [CrossRef]

20. Marecos, J.; Castanheta, M. Estudo do Comportamento de Estruturas sob a Ação do Sismo de 28 de Fevereiro de 1969; LNEC: Lisboa, Portugal, 1970.

21. Furtado, A.; Rodrigues, H.; Varum, H.; Costa, A. Evaluation of different strengthening techniques' efficiency for a soft storey building. Eur. J. Environ. Civ. Eng. 2017, 21, 371-388. [CrossRef] 
22. Benedetti, D.; Petrini, V. Sulla vulnerabilita sismica di edifici in muratura: Proposta su un metodo di valutazione. L'industria Delle Costr. 1984, 149, 66-74.

23. Dolce, M.; Kappos, A.; Masi, A.; Penelis, G.; Vona, M. Vulnerability assessment and earthquake damage scenarios of the building stock of Potenza (Southern Italy) using Italian and Greek methodologies. Eng. Struct. 2006, 28, 357-371. [CrossRef]

24. Cosenza, E.; Del Vecchio, C.; Di Ludovico, M.; Dolce, M.; Moroni, C.; Prota, A.; Renzi, E. The Italian guidelines for seismic risk classification of constructions: Technical principles and validation. Bull. Earthq. Eng. 2018, 16, 5905-5935. [CrossRef]

(C) 2020 by the authors. Licensee MDPI, Basel, Switzerland. This article is an open access article distributed under the terms and conditions of the Creative Commons Attribution (CC BY) license (http://creativecommons.org/licenses/by/4.0/). 